\title{
Tubulostromal Adenocarcinoma
}

National Cancer Institute

\section{Source}

National Cancer Institute. Tubulostromal Adenocarcinoma. NCI Thesaurus. Code C80356.

A malignant ovarian epithelial tumor. It has been described in mice and rats and is characterized by marked pleomorphism, atypia, and an infiltrative growth pattern. 